\title{
Causes and risk factors of reintubation in Shahid Madani cardiac surgery ICU during 2012-2013
}

\author{
Kamran Shadvar ${ }^{1}$, Ata Mahmoodpoor ${ }^{2}$, Mohammad Reza Nazari ${ }^{3}$, Hadi Hamishehkar ${ }^{4}$, Issa \\ Bilejani², Bahman Naghipour², Reza Movassaghi ${ }^{*}$ \\ 1. Cardiovascular Research Center, Tabriz University of Medical Sciences, Tabriz, Iran \\ 2. Department of Anesthesiology and Intensive Care, Tabriz University of Medical Sciences, Tabriz, Iran \\ 3. Faculty of Medicine, Tabriz University of Medical Sciences, Tabriz, Iran \\ 4. Applied Drug Research Center, Tabriz University of Medical Sciences, Tabriz, Iran
}

\begin{abstract}
Background: Extubation failure rate is one of the criteria for assessing the quality of care in intensive care unit (ICU) and higher or lower extubation failure rates indicate longer mechanical ventilation or inappropriate weaning criteria of patients, respectively. The aim of the present study was to evaluate the rate and causes of extubation failure in the cardiac surgery ICU of Tabriz Shahid Madani hospital during 2012-2013. Methods: In a cross-sectional study during 2012-2013, all intubated adult patients (over 18 years old) after cardiac surgery admitted to ICU who were re-intubated within 72 hours after extubation were studied. Results: Overall, 31 patients had the inclusion criteria. Extubation failure rate during one year was $2.45 \%$. Extubation failure causes were hypoxemia, cardiopulmonary arrest, sepsis, acute renal failure, re-operation, shock, acute respiratory distress syndrome, pneumonia, seizures, decreased level of consciousness, copious secretion, and severe agitation. Re-intubation risk factors included chronic obstructive pulmonary disease, diabetes mellitus, renal failure, heart failure, ARDS, pneumonia, intra-aortic balloon pump, acute coronary syndrome and shock. The mean duration of mechanical ventilation before extubation was $2.3 \pm 3.1$ days. The overall mortality rate of studied patients was $26 \%$ with coronary artery bypass grafting surgery as the most common cause.

Conclusions: During 2012 and 2013, the extubation failure rate in the cardiac surgery ICU was $2.45 \%$. The most common causes of extubation failure in this setting were hypoxemia and pneumonia. Moreover, the most common risk factors for re-intubation were diabetes mellitus and renal failure.
\end{abstract}

Keywords: Airway Extubation failure; Cardiac surgery; ICU;

\section{Introduction}

Mechanical ventilation is an important tool to support life, and used in the majority of patients admitted to the intensive care unit (ICU) (1-3). Separating patients from mechanical ventilation (i.e., weaning) is the process of full respiratory support to spontaneous breathing which includes two separate stages: liberation and extubation. Late separating patients from mechanical ventilation increases the risk of infection, gastrointestinal

\section{Corresponding author:}

Reza Movassaghi

Department of Anesthesiology, Tabriz University of Medical Sciences, Tabriz, Iran

Email: rz_movassaghi@yahoo.com Phone: +989141121090

Receive date: 2016-02-7| Accept date: 2016-03-24| Publish date: 2016-04-19

DOI: 10.7575/aiac.abcmed.16.04.02.06 
bleeding, deep vein thrombosis, health care costs, and length of stay in ICU (4-6).

Extubation failure is an inability to have sustained spontaneous respiration after removing artificial airway, endotracheal tube or tracheostomy, and the need for re-intubation in a specific period of time ranging from 24 to 72 hours (4-7). Causes of extubation failure include upper airway obstruction, failure to discharge respiratory secretions, respiratory failure, hypoxemia, hypercapnia, inability to protect the airway, heart failure, neurological disorders, etc. $(8,9)$. Extubation failure rate is calculated in percentage by dividing the number of re-intubated patients on the number of extubated patients and the standard value of failure rate is $5-20 \%$. This is one of the criteria for assessing the quality of care in the ICU, and higher or lower extubation failure rates indicate longer mechanical ventilation or inappropriate weaning criteria of patients, respectively $(10,11)$.

The aim of the present study was to evaluate the rate and causes of extubation failure in the cardiac surgery ICU of Tabriz Shahid Madani hospital during 2012-2013.

\section{Materials and Methods}

The present study was approved by the Ethics Committee of Tabriz University of Medical Sciences, and informed consent was obtained from the patients. In a cross-sectional study during 2012-2013, all intubated adult patients (over 18 years old) after cardiac surgery admitted to ICU of the Tabriz Shahid Madani hospital who were re-intubated within 72-hours after extubation were studied. Patients were excluded if they were admitted to the cardiac surgery ICU from other wards for any reason or after non-cardiac surgery, were transferred to the operating room for another surgery within the first 72 hours after cardiac surgery and intubated after anesthesia, disagree to participate in the study.
Data were presented as mean \pm standard deviation (SD), or frequency (percentage). Statistical analysis was performed with SPSS 17.0 (SPSS, Chicago, Illinois) using independent T-test for quantitative variables and chi-square or Fisher's exact test for qualitative variables. A $P$ value $<0.05$ was considered statistically significant.

\section{Results}

Overall, 31 patients of 1264 intubated patients admitted to the ICU of Tabriz Shahid Madani hospital had the inclusion criteria. The demographic characteristics of patients are shown in Table 1. Extubation failure rate during one year was $2.45 \%$. Extubation failure causes were hypoxemia, cardiopulmonary arrest, sepsis, acute renal failure, re-operation, shock, acute respiratory distress syndrome (ARDS), pneumonia, seizures, decreased level of consciousness, copious secretion, and severe agitation (Table 2).

\begin{tabular}{ccc}
\hline & $\mathrm{n}(\%)$ & Mean \pm SD \\
\hline Sex & & \\
Male & $18(58.1)$ & \\
Female & $13(41.9)$ & \\
Age & & $63.6 \pm 11.9$ \\
$36-55 \mathrm{y}$ & $9(29)$ & \\
$56-70$ & $13(42)$ & \\
$\geq 71$ & $9(29)$ & \\
BMI & & \\
Normal & $9(29)$ & \\
Overweight & $19(61.3)$ & \\
Obese & $3(9.7)$ & \\
LVEF & & $43 \pm 12.3$ \\
Time to Reintubation & & \\
First 24h & $20(64.5)$ & \\
Second 24h & $1(3.2)$ & \\
Third 24h & $10(32.3)$ & \\
\hline
\end{tabular}

Table 1: Demographic Characteristics of the patients

Re-intubation risk factors included chronic obstructive pulmonary disease (COPD), dia 
betes mellitus, renal failure, heart failure, ARDS, pneumonia, intra-aortic balloon pump, acute coronary syndrome and shock (Table 3 ). The mean duration of mechanical ventilation before extubation was $2.3 \pm 3.1$ days. The overall mortality rate of studied patients was $26 \%$ with coronary artery bypass grafting (CABG) surgery as the most common cause (Table 4).

\begin{tabular}{lcc}
\hline & $\mathrm{n}$ & $\%$ \\
\hline Hypoxemia & 6 & 19.4 \\
Cardiac arrest & 3 & 9.7 \\
Sepsis & 1 & 3.2 \\
Acute Renal Failure & 1 & 3.2 \\
Reoperation & 4 & 12.9 \\
Shock & 1 & 3.2 \\
ARDS & 1 & 3.2 \\
Pneumonia & 6 & 19.4 \\
Seizure & 1 & 3.2 \\
Loss of consciousness & 4 & 12.9 \\
Copious secretion & 2 & 6.5 \\
Agitation & 1 & 3.2 \\
\hline
\end{tabular}

Table 2: Extubation failure causes

\begin{tabular}{lcc}
\hline & $\mathrm{n}$ & $\%$ \\
\hline COPD & 4 & 12.9 \\
Diabetes & 12 & 38.7 \\
Renal Failure & 10 & 32.2 \\
Heart Failure & 8 & 19.2 \\
ARDS & 1 & 3.2 \\
Pneumonia & 1 & 3.2 \\
IABP & 1 & 3.2 \\
ACS & 4 & 12.9 \\
Shock & 1 & 3.2 \\
\hline
\end{tabular}

Table 3: Re-intubation risk factors

ACS: Acute Coronary Syndrome, IABP: IntraAortic Balloon Pump

\section{Discussion}

Delayed or failed extubation leads to longer ICU stay, need for tracheostomy, increase in the cost of treatment, and mortality. The percentage of extubation failure in patients in different studies varies between $6-47 \%(4,12)$. In our study, during one year the rate of re-intubation in the cardiac surgery ICU

\begin{tabular}{lccc} 
& $\mathrm{n}$ & died & Mortality\% \\
\hline CABG & 16 & 5 & 31.2 \\
MVR or AVR & 11 & 1 & 9 \\
Other operations & 4 & 2 & 50 \\
Total & 31 & 8 & 26 \\
\hline
\end{tabular}

Table 4: Re-intubation mortality included type of operation

MVR: Mitral valve replacement; AVR: Aortic valve replacement

was $2.45 \%$. The rate of standard international re-intubation has been reported $5-20 \%$ in different studies $(10,11)$. This difference might be due to the less illness of patients or strict protocols of patients who were under studying for extubation. High rate of re-intubation has been also attributed to selecting patients from different ICU wards (13).

Numerous studies have demonstrated that the most common cause of re-intubation was aspiration of frequent secretions $(12,13$, 14). In contrast, the present study showed that hypoxemia and pneumonia were the most common causes of re-intubation in the cardiac surgery ICU setting. Similarly, Frutos-Vivar et al. detected respiratory failure and hypoxemia as two common causes of re-intubation (14).

Our study revealed that decreased level of consciousness was a risk factor for reintubation. This finding is consistent with that of the previous reports $(13,15,16)$. Contrarily, Frutos-Vivar and colleagues disclosed that reintubation rate was not associated with level of consciousness, and amount of endotracheal secretions (14). Likewise, Coplin et al. found that Glasgow Coma Scale (GCS) score <8 resulted in longer intubation time; however, decreased level of consciousness was not a risk factor for re-intubation (17). This difference might be due to the fact that GCS score does not necessarily specify neurological function in airway reflexes. Therefore, it seems that other methods of assessing the state of consciousness, such as RASS (Richmond 
Agitation-Sedation Scale) can be used instead of GCS criteria.

Heart failure was among the risk factors for re-intubation in our study. Similarly, in a study on patients requiring re-intubation within 72 hours after extubation, congestive heart failure was a factor for extubation failure in almost one fourth of cases (4). Additionally, the most common risk factor for re-intubation in our study was diabetes mellitus which might be due to the higher prevalence of the disease in the study population.

\section{Conclusion}

During 2012 and 2013, the extubation failure rate in the cardiac surgery ICU was $2.45 \%$. The most common causes of extubation failure in this setting were hypoxemia and pneumonia. Moreover, the most common risk factors for reintubation were diabetes mellitus and renal failure. Further prospective studies with larger sample size are required to delineate the precise rate of re-intubation in our hospital setting.

\section{References}

1. Chao DC, Scheinhorn DJ. Weaning from mechanical ventilation. Crit Care Clin. 1998;14:799-817.

2. Eskandar N, Apostolakos MJ. Weaning from mechanical ventilation. Crit Care Clin. 2007;23:263-74.

3. Lellouche F, Mancebo J, Jolliet P, Roeseler J, Schortgen F, Dojat M, Cabello B, Bouadma L, Rodriguez P, Maggiore S, Reynaert M, Mersmann S, Brochard L. A multicenter randomized trial of computer-driven protocolized weaning from mechanical ventilation. Am J Respir Crit Care Med. 2006;174:894-900.

4. Epstein SK, Ciubotaru RL. Independent effects of etiology of failure and time to reintubation on outcome for patients failing extubation. Am J Respir Crit Care Med. 1998;158:489-93.

5. Esteban A, Alía I, Gordo F, Fernández R, Solsona JF, Vallverdú I, Macías S, Allegue JM, Blanco J, Carriedo D, León M, de la Cal MA, Taboada F, Gonzalez de Velasco J, Palazón E, Carrizosa F, Tomás R, Suarez J, Goldwasser RS. Extubation outcome after spontaneous breathing trials with T-tube or pressure support ventilation. Am J Respir Crit Care Med. 1997;156:459-65.

6. Martinez A, Seymour C, Nam M. Minute ventilation recovery time: a predictor of extubation outcome. Chest. 2003;123:1214-21.

7. Smina M, Salam A, Khamiees M, Gada P, Amoateng-Adjepong Y, Manthous CA. Cough peak flows and extubation outcomes. Chest. 2003;124:262-8.

8. Kulkarni AP, Agarwal V. Extubation failure in intensive care unit: predictors and management. Indian J Crit Care Med. 2008;12:1-9.

9. Yazdanian F, Azarfarin R, Aghdaii N, Faritous SZ, Motlagh SD, Panahipour A. Cardiac variables as main predictors of endotracheal reintubation rate after cardiac surgery. J Tehran Heart Cent. 2013;8:42-7.

10. Rothaar RC, Epstein SK. Extubation failure: magnitude of the problem, impact on outcomes, and prevention. Curr Opin Crit Care. 2003;9:59-66.

11. Cabello B, Roche-Campo F, Mancebo J. Weaning from Mechanical Ventilation. In: Vincent JL, Abraham E, Moore FA, Kochanek PM, Fink MP, editors. Textbook of Critical Care. sixth edition. Philadelphia, PA: Saunders; 2011. p. 342346.

12. Gowardman JR, Huntington D, Whiting J. The effect of extubation failure on outcome in a multidisciplinary Australian intensive care unit. Crit Care Resusc. 2006;8:328-33.

13. Mokhlesi B, Tulaimat A, Gluckman TJ, Wang Y, Evans AT, Corbridge TC. Predicting extubation failure after successful completion of a spontaneous breathing trial. Respir Care. 2007;52:1710-7. 
14. Frutos-Vivar F, Ferguson ND, Esteban A, Epstein SK, Arabi Y, Apezteguía C, González M, Hill NS, Nava S, D'Empaire $G$, Anzueto A. Risk factors for extubation failure in patients following a successful spontaneous breathing trial. Chest. 2006;130:1664-71.

15. Khamiees M, Raju P, DeGirolamo A, Amoateng-Adjepong Y, Manthous CA. Predictors of extubation outcome in patients who have successfully completed a spontaneous breathing trial. Chest. 2001;120:1262-70.

16. Namen AM, Ely EW, Tatter SB, Case LD, Lucia MA, Smith A, Landry S, Wilson JA, Glazier SS, Branch CL, Kelly DL, Bowton DL, Haponik EF. Predictors of successful extubation in neurosurgical patients. Am J Respir Crit Care Med. 2001;163:658-64.

17. Coplin WM, Pierson DJ, Cooley KD, Newell DW, Rubenfeld GD. Implications of extubation delay in brain-injured patients meeting standard weaning criteria. Am J Respir Crit Care Med. 2000;161:1530-6. 